\title{
High-precision relocation of seismic sequences above a dipping Moho: the case of the January-February 2014 seismic sequence on Cephalonia island (Greece)
}

\author{
V. K. Karastathis, E. Mouzakiotis, A. Ganas, and G. A. Papadopoulos \\ National Observatory of Athens, Institute of Geodynamics, Lofos Nymfon, P.O. Box 20048, 11810 Athens, Greece \\ Correspondence to: V. K. Karastathis (karastathis@ @oa.gr) \\ Received: 5 August 2014 - Published in Solid Earth Discuss.: 2 September 2014 \\ Revised: 15 December 2014 - Accepted: 23 December 2014 - Published: 12 February 2015
}

\begin{abstract}
Detailed velocity structure and Moho mapping is of crucial importance for a high precision relocation of seismicity occurring out of, or marginal to, the geometry of seismological networks. Usually the seismographic networks do not cover the boundaries of converging plates such as the Hellenic arc. The crustal thinning from the plate boundary towards the back-arc area creates significant errors in accurately locating the earthquake, especially when distant seismic phases are included in the analysis. The case of the Cephalonia (Ionian Sea, Greece) sequence of JanuaryFebruary 2014 provided an excellent example where the hypocentral precision was greatly affected by the crustal thinning from the plate boundary at the Ionian sea towards the Aegean sea. This effect was examined in detail by testing various velocity models of the region in order to determine an optimal model. Our tests resulted in the adoption of a velocity model that resembles the crustal thinning of the region. Then, a relocation procedure was performed in the Cephalonia sequence for the time period of 26 January to 15 May 2014 by applying probabilistic non-linear location algorithms. The high-precision relocation resulted in an improved spatial distribution of the seismicity with respect to the preliminary locations and provided a reliable basis to examine seismotectonic implications of the Cephalonia sequence.
\end{abstract}

\section{Introduction}

On 26 January (13:55:42 and 18:45:08 GMT) and 3 February 2014 (03:08:44 GMT), western Cephalonia, an island on the
Ionian Sea (Greece) (Fig. 1), was ruptured by three strong earthquakes of magnitudes $M_{\mathrm{w}}=6.0, M_{\mathrm{w}}=5.3$, and $M_{\mathrm{w}}=$ 5.9 (Table 1, Fig. 2). The two strongest earthquakes caused considerable damage in buildings and infrastructure as well as several types of ground failures (rockfalls, landslides, soil liquefaction) on the Paliki peninsula, mainly in Lixouri and its surrounding villages (Papadopoulos et al., 2014; Valkaniotis et al., 2014) (Fig. 1). The peak ground acceleration (PGA) recorded in several localities at accelerometric stations, operated by the National Observatory of Athens, Institute of Geodynamics (NOAGI) (NOA web report, 2014a, b) and the Institute of Engineering Seismology and Earthquake Engineering (EPPO-ITSAK, 2014a, b) reached up to 0.56 and $0.77 \mathrm{~g}$ in Lixouri during the first and third earthquake, respectively. Since only three permanent seismic stations existed in Cephalonia, on 28 and 29 January 2014 four portable seismic stations (Fig. 2) were installed by NOAGI in the aftershock zone of western Cephalonia with the aim of improving the monitoring capabilities.

Cephalonia has been hit by many strong earthquakes in the past (Ambraseys, 2009; Papazachos and Papazachou, 2003). In the instrumental era of seismology, the most important activity was a series of very strong, lethal earthquakes that ruptured eastern and central Cephalonia, with the largest $\left(M_{\mathrm{S}}=7.2\right)$ occurring on 12 August 1953. Large earthquakes occurred off the coast of western Cephalonia in 1972 and 1983 (Scordilis et al., 1985). The very high seismicity of Cephalonia is controlled by two major seismotectonic structures. The first is the right-lateral strike-slip Cephalonia Transform Fault zone (CTFZ) comprising of the NNE-SSW trending Lefkada segment in the north and the NE-SW trending Cephalonia segment in the south (Louvari 


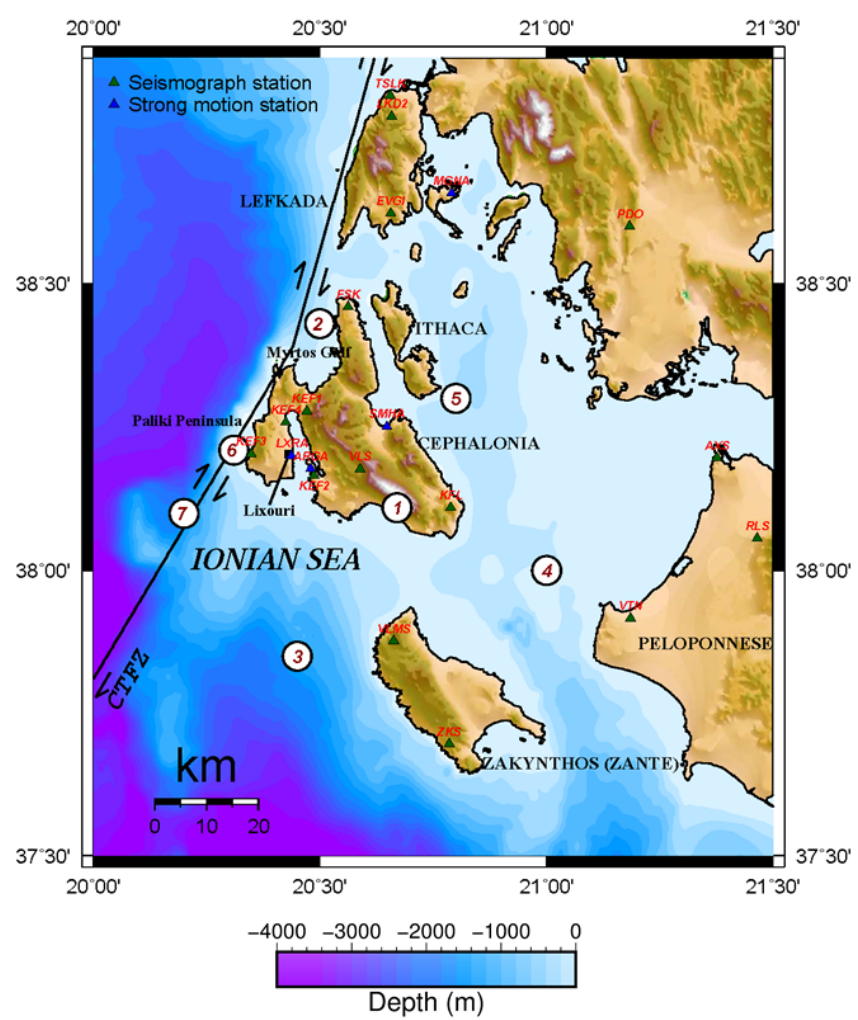

Figure 1. Location map of the study region. The Cephalonia Transform Fault zone (CTFZ) is also indicated on the map. The seismographic stations of the Hellenic Unified Seismological Network (HUSN) are depicted with green-colored triangles and the strong motion stations with blue ones. Significant earthquakes after 1900 (Papazachos et al., 2010) are shown as white circles: (1) 24 January $1912, M=6.8$; (2) 9 August $1953, M=6.4$; (3) 11 August $1953, M=6.8$; (4) 12 August 1953, $M=6.3$; (5) 12 August 1953, $M=7.2$; (6) 17 September $1972, M=6.3$; (7) 17 January 1983 , $M=7.0$.

et al., 1999) (Fig. 1). The strong $\left(M_{\mathrm{w}}=6.2\right)$ earthquake on 14 August 2003 ruptured off the coast of western Lefkada along the Lefkada segment of CTFZ (Fig. 1; Papadopoulos et al., 2003). Recently, Papadopoulos et al. (2014) proposed, based on the spatial pattern of the Cephalonia 2014 earthquake sequence, that the Lefkada segment does not terminate at the NW side of Cephalonia, as previously thought, but extends into western Cephalonia (Fig. 1). A second major structure that controls the seismicity of the area is the northeastern subduction of the Ionian segment of the Hellenic Arc beneath Cephalonia (Sachpazi et al., 2000), thus making up a highly complex seismotectonic setting.

The January-February 2014 seismic sequence is the first one that ruptured western Cephalonia and was recorded by modern seismograph instruments. Therefore, the study of this sequence is of particular importance to better understand the seismicity of Cephalonia. To this aim we performed a high-precision relocation of the seismic sequence of more than 3300 events of magnitude range $M=1.0-6.0$ from 26 January to 15 May 2014. Then, relocation results were utilized to interpret the seismotectonics of the 2014 activity as well as the geometry and kinematics of the major structure of the CTFZ.

\section{The problem of location}

The routine determination of earthquake hypocentral parameters usually suffers from significant errors.

More specifically, the main sources of errors for an accurate determination of the hypocentral parameters are (a) picking errors, (b) false identification of the seismic phases, (c) insufficient number of phases, (d) deficient azimuthal coverage of the seismographic network, and finally (e) use of non-effective seismic velocity models that are usually oversimplified (often 1-D) without adequate information for the velocity structure and the lateral velocity heterogeneities. It is a common practice that unified, regional 1-D velocity models are in use, which is also the case of NOAGI for the daily seismicity monitoring of Greece (see Fig. 3). Such velocity models deviate considerably from the local velocity structure of an area, especially outside of the area covered by the network.

Although it is feasible to derive reliable seismic velocity models for areas on a local scale through the implementation of nonlinear inversion techniques that simultaneously invert travel-time data for the hypocentral parameters and seismic velocity determination (Kissling et al., 1994; Kissling, 1995; Thurber, 1993; Koulakov, 2009), it is difficult to perform this practice on a regional scale. Additionally, information coming from crustal seismic surveys is usually useful to build only local velocity models. The crustal mapping based on gravity models suffers from intrinsic ambiguity and the resolution of the seismic velocity global models is too low (Koulakov and Sobolev, 2006).

Inaccurate hypocenter determinations become more acute in the presence of strong structural anomalies and variations that make a structure different from the horizontally layered Earth. For example, crustal thickness is strongly affected in areas situated in the vicinity of convergent plate boundaries. This is the case for the thick continental Aegean crust in the vicinity of the Hellenic subduction zone. In fact, the compressional regime along the Hellenic Arc led to folding and thin-skinned tectonics as well as to the creation of the Mediterranean ridge, which evolved to an accretionary prism, and to subsequent thickening of the crust (Underhill, 1989; Yem et al., 2011). Crustal surveys have shown that in western Greece, where the oceanic crust of the African plate is sliding beneath the Aegean area, the continental crustal thickness exceeds $40 \mathrm{~km}$ and becomes progressively thinner to the east (Makris, 1978; Tsokas and Hansen, 1997; Papazachos and Nolet, 1997; Tiberi et al., 2001; Karagianni et al., 2005; Pearce et al., 2012; Makris et al., 2013). At the southern Aegean Sea the crustal thickness reaches values as 
Table 1. Focal parameters of the three strong earthquakes of the January-February 2014 Cephalonia seismic sequence as preliminary calculated by NOA. The revised solutions are also shown.

\begin{tabular}{llllllll}
\hline Date & Time & $\begin{array}{l}\text { Lat } \\
(\mathrm{deg})\end{array}$ & $\begin{array}{l}\text { Long } \\
(\mathrm{deg})\end{array}$ & $M_{\mathrm{W}}$ & $M_{\mathrm{L}}$ & $\begin{array}{r}h \\
(\mathrm{~km})\end{array}$ & \\
\hline \multirow{2}{*}{26.01 .14} & \multirow{2}{*}{13.55 .42 .7} & 38.2190 & 20.5322 & \multirow{2}{*}{6.0} & 5.8 & $\begin{array}{r}16.4 \\
16.5\end{array}$ & $\begin{array}{l}\text { Preliminary } \\
\text { Relocated }\end{array}$ \\
\hline \multirow{2}{*}{26.01 .14} & \multirow{2}{*}{18.45 .08 .3} & 38.2282 & 20.4614 & & & & \\
& & 38.2514 & 20.4555 & 5.3 & 5.1 & $\begin{array}{r}16.5 \\
12.5\end{array}$ & $\begin{array}{l}\text { Preliminary } \\
\text { Relocated }\end{array}$ \\
\hline \multirow{2}{*}{03.02 .14} & \multirow{2}{*}{03.08 .44 .7} & 38.2462 & 20.3958 & \multirow{2}{*}{5.9} & 5.7 & $\begin{array}{r}11.3 \\
4.6\end{array}$ & $\begin{array}{l}\text { Preliminary } \\
\text { Relocated }\end{array}$ \\
\hline
\end{tabular}
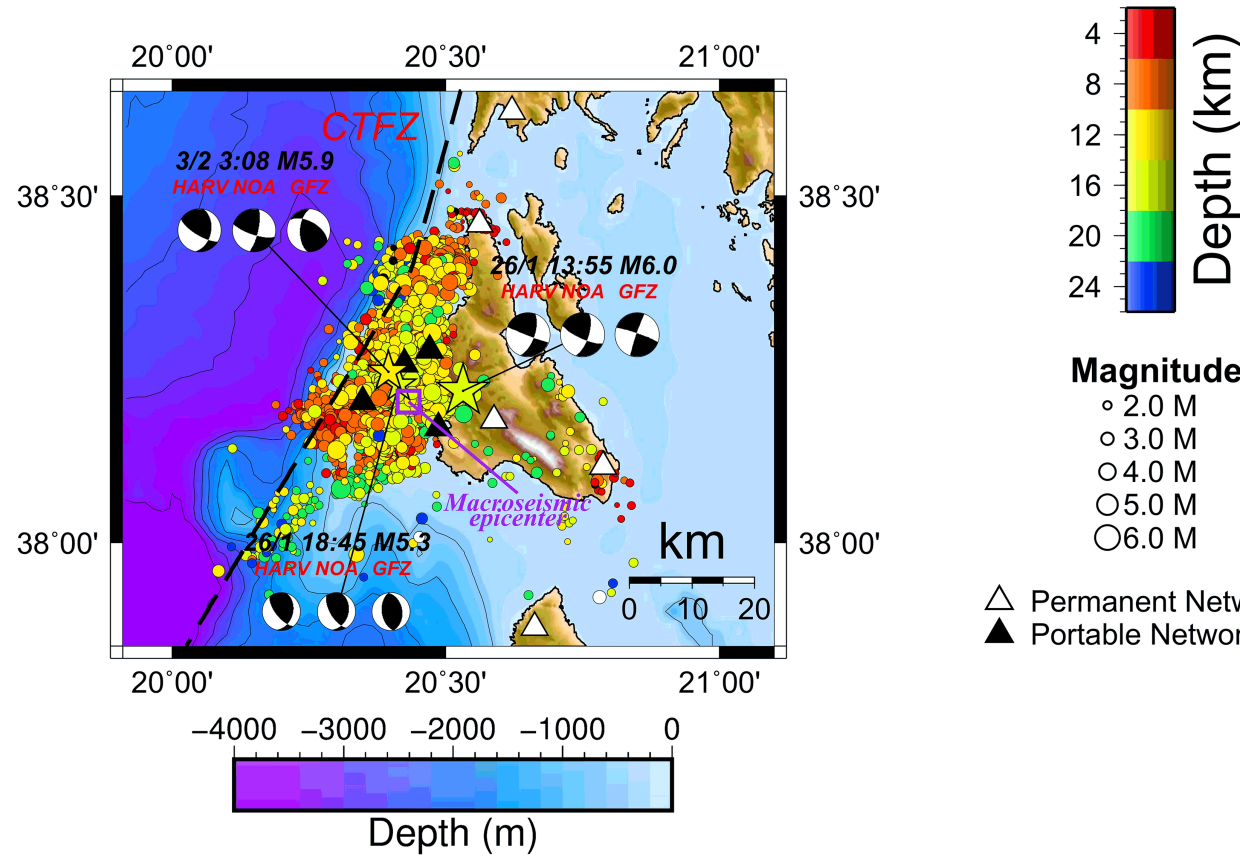

\section{$\triangle$ Permanent Network}

$\triangle$ Portable Network

Figure 2. Map of the aftershock sequence from 26 January to 15 May 2014 as determined by the National Observatory of Athens. The moment tensor solutions for the largest events as calculated by the Global Centroid Moment Tensor Project: Harvard University, USA (HARV), National Observatory of Athens (NOA), and the German Research Centre for Geoscience (GFZ).

low as $20 \mathrm{~km}$ or less (Makris, 1975, 1976, 1977; Bohnhoff et al., 2001; Tirel et al., 2004). A similar pattern of crustal thinning to the east but with shallower Moho depths $(28 \mathrm{~km}$ under Cephalonia) was proposed by Sodoudi et al. (2006). Thus, when an earthquake occurs in the thick part of the crust and the paths of the first arriving waves pass through the Moho as it progressively becomes shallower, the traveltime errors may increase considerably with the increase of the epicentral distance. In contrast, shallower events are not so strongly affected, particularly in short epicentral distances since only Pg phases are actually picked. This structure causes an asymmetrical shape to the head-wave wavefront. Due to this structure, the adoption of a 1-D velocity model (see NOA-IG model in Fig. 3) can cause systematic traveltime residuals at the event's location.

\section{Analysis of seismological data}

The Cephalonia 2014 seismic sequence was examined exactly in this context. The first strong earthquake on $26 \mathrm{Ja}$ nuary 2014 was recorded by the permanent stations of the HUSN (Hellenic Unified Seismological Network, 2015) before the installation of the portable network in Cephalonia. The focus of that event was preliminary determined by NOAGI at a location situated about $5 \mathrm{~km}$ NNE from the city of Argostoli and at a focal depth of $h=21 \mathrm{~km}$ (Fig. 2) (Table 1). This location clearly falls outside of the aftershock cloud as well as far from Lixouri, where the macroseismic epicenter was determined according to the field observations performed by Papadopoulos et al. (2014) (Fig. 2). The epicentral area is situated at the geometrical edge of the 


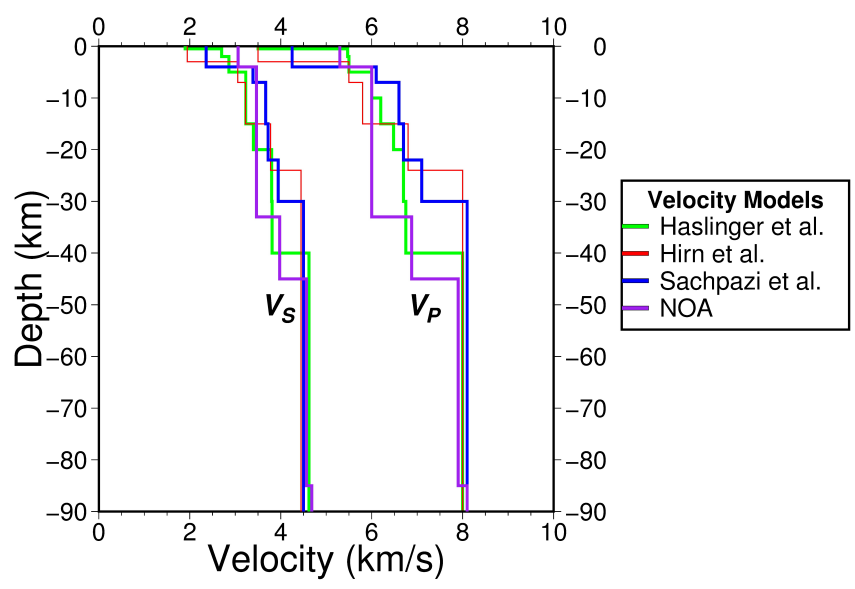

Figure 3. The seismic $P$ - and $S$-wave velocity models tested for the relocation of the aftershock sequence. Green, blue, and red correspond to velocity models proposed by Haslinger et al. (1999), Sachpazi et al. (2000), and Hirn et al. (1996), respectively. The model routinely used by NOAGI is marked in purple. The $S$-wave model of NOAGI is based on a constant $V_{\mathrm{p}} / V_{\mathrm{s}}=1.73$. For Hirn et al. (1996) and Sachpazi et al. (2000), a constant $V_{\mathrm{p}} / V_{\mathrm{s}}$ ratio of 1.80 was used as proposed by previous studies (Hatzfeld et al., 1995; Le Meur et al., 1997; see also Haslinger et al., 1999). Haslinger et al. (1999) provide a separate velocity model.

permanent network, meaning that no stations were situated to the west of the earthquake focus. Consequently, the azimuthal coverage was poor, leading to unstable location solutions. In addition, the preliminary solution included several phases from significantly large epicentral distances extending up to $360 \mathrm{~km}$, where the crustal thickness was significantly smaller than that in the subduction regime of western Cephalonia. The 1-D model used by NOAGI (Fig. 3), with the Moho boundary placed at $40 \mathrm{~km}$, could not match Pn phase data from areas of thin crust, particularly at large epicentral distances. Therefore, significant errors were involved and consequently the epicenter of the first strong earthquake was shifted substantially to the east. Its aftershocks, however, were not shifted significantly because their small magnitudes prevented the use of many distant stations where the velocity model was inadequate. In a next paragraph it is explained more precisely how errors are introduced in the epicentral solution.

The preliminary epicenter of the strong $\left(M_{\mathrm{w}}=5.3\right)$ aftershock on 26 January 2014 (18:45:08 GMT) was located in a noticeably better agreement to the macroseismic epicenter (Fig. 2), although it was calculated before the installation of the portable network in Cephalonia. This is explained by the fact that its actual focal depth was shallower than that of the first strong earthquake. It is also worth mentioning that $1 \mathrm{~s}$ after the first strong shock on 26 January 2014, another strong aftershock occurred. Unfortunately, the waveform of this event partially overlapped with the waveform of the first strong shock, making an accurate estimation of its local and moment magnitudes quite difficult. The estimation of its duration magnitude is $M_{\mathrm{d}}=5.0$. The existence of this event, although not reported in earthquake catalogs, justifies the accounts of local people of another shock strongly felt in Cephalonia a few seconds after the first major event.

After the installation of the portable network in western Cephalonia, the maximum azimuthal gap was decreased significantly, becoming less than $180^{\circ}$ for most of the seismic events. The preliminary focus of the strong earthquake $\left(M_{\mathrm{w}}=5.9\right)$ on 3 February 2014 was located at a shallower depth $(h=11 \mathrm{~km}$, Table 1$)$ but within the aftershock cloud (Fig. 2) and at a position close to its macroseismic epicenter, which again was determined to be (Papadopoulos et al., 2014) in Lixouri.

To effectively relocate the hypocenter data of the sequence one may use a velocity model resembling as much as possible the real velocity structure. An effective model can compensate for most of the systematic time residuals created at distant stations. An alternative method is to use a 1-D model to find the epicentral distance range where the effect of the inclined Moho does not considerably affect the location accuracy. This approach limits the seismic phases taken into account. It is reasonably expected that the two different approaches should lead to quite similar results.

\section{Selection of a velocity model - relocation of the Cephalonia 2014 earthquake sequence}

\subsection{Proposed models for the region}

For western Greece, including Cephalonia, few seismic velocity models have been proposed (Hirn et al., 1996; Haslinger et al., 1999; Sachpazi et al., 2000). The model proposed by Hirn et al. (1996) was directly based on the results of the crustal seismic surveys carried out in 1992 within the project STREAMERS. The profile ION-7, with an azimuth of N62, was conducted offshore between Cephalonia and Zakynthos (Zante) islands, starting from the deep Ionian basin and reaching the western Gulf of Patras for a total length of $180 \mathrm{~km}$ (see maps in Hirn et al., 1996). For the data acquisition, the motor vessel (M/V) Bin Hai 511 from Geco-Prakla was used with a 36-airgun array (for processing details see also in Kokinou et al., 2005). The seismic reflection profile acquired provided useful information for the shallower structure. However, no precise information was gathered for the Moho interface. To get a rough estimate of the Moho depth, Hirn et al. (1996) performed ray-tracing modeling of the wide-angle travel-time data recorded at distant onshore stations positioned on the Greek mainland. Those stations were located only at the eastern side of the profile. Further assumptions were made for the velocity values beneath the $7 \mathrm{~km}$ depth. Thus, these authors discussed a model with the lower crustal interface $\left(V_{\mathrm{p}}\right.$ between 5.8 and $\left.6.8 \mathrm{~km} \mathrm{~s}^{-1}\right)$ at $15 \mathrm{~km}$ depth and the Moho boundary at $25 \mathrm{~km}$. Since the 
structure in this model was almost horizontal, the 1-D model in Fig. 3 can be easily derived.

The velocity model of Haslinger et al. (1999) (Fig. 3) was built for the eastern region of Lefkada (western Greece), which as regards to the Cephalonia 2014 sequence, concentrates a high percentage of the ray paths between the earthquakes and the stations. This model was based on a passive experiment and was built as a "1-D minimum velocity model" for this region by the VELEST algorithm (Kissling et al., 1994; Kissling, 1995) and used in a following stage as the initial model in the local earthquake tomography method and SIMULPS code (Thurber, 1993; Eberhart-Phillips, 1990, 1993), implemented to calculate the 3-D crustal velocity structure. The SIMULPS code uses a linearized damped least-square inversion to solve the non-linear problem of the hypocentral location and velocity model. Because of this non-linear nature of the problem, the initial velocity model and the initial hypocenter locations in the inversion procedure should be as close as possible to their true values. The "1-D minimum velocity model" calculated by the VELEST algorithm can provide a good approximation and be used as an initial velocity model. The minimum $1-\mathrm{D}$ velocity models are usually used for seismicity relocation (e.g., Lippitsch et al., 2005; Ganas et al., 2014).

The model proposed by Sachpazi et al. (2000) (Fig. 3) was also created by the VELEST algorithm in order to be used as the initial model in a 3-D local earthquake tomography to determine the velocity structure of the studied area. The procedure for the construction of a 1-D minimum velocity model is highly dependent on the selection of an initial model (Karastathis et al., 2011) and, therefore, it is usually based on the results of seismic profiles. Sachpazi et al. (2000) based their initial model on the seismic profiles presented by Hirn et al. (1996).

For the adoption of an appropriate seismic velocity model, we compared the three 1-D models mentioned above (Fig. 3). As we will see later in detail, the model that performed better was that proposed by Haslinger et al. (1999). With a vertical velocity gradient based on Haslinger et al. (1999) we constructed, tested, and adopted a 2-D velocity model with a non-horizontal Moho boundary based on Papazachos and Nolet (1997). Figure 4 shows the vertical cross section of the 2-D model.

\subsection{Synthetic data}

Before comparing the performance of these models, we examine the influence on the location procedure of the nonhorizontal Moho boundary in the Aegean region. More specifically, in order to assess the impact of the errors imposed in the earthquake location procedure by the adoption of a simplified 1-D model in the presence of a non-horizontal Moho structure, we constructed synthetic arrival times for the adopted model using the 3-D version of the eikonal finitedifference scheme of Podvin and Lecomte (1991) and esti-
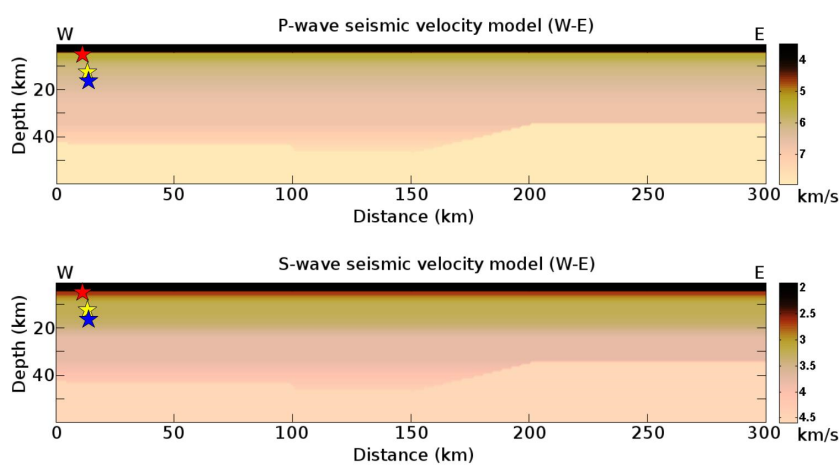

Figure 4. The 2-D velocity model tested to assess the influence of Moho structure. The Moho boundary has been based on the results of Papazachos and Nolet (1997). The position of Cephalonia is between 0 and $50 \mathrm{~km}$. The hypocenters of the major events are shown with stars: blue for the event of 26 January $2014\left(M_{\mathrm{W}}=6.0\right)$, yellow for the aftershock on 26 January $2014\left(M_{\mathrm{W}}=5.3\right)$, and red for the event of 3 February $2014\left(M_{\mathrm{W}}=5.9\right)$.

mated the time differences for both a horizontal and a nonhorizontal Moho structure. The velocity gradient was based on Haslinger et al. (1999). The 2-D model with the nonhorizontal Moho boundary is shown in Fig. 4 and the results of the comparison with the respective 1-D model are depicted in Fig. 5. As one may expect, the time difference is zero only when the first arrivals are also zero due to the Pg seismic phases. Obviously, the shallower events, with focal depth between 5 and $10 \mathrm{~km}$ are not, or only slightly, affected, particularly when they do not bare enough energy to travel at long epicentral distances. As a result, the majority of the shallow aftershocks remain unaffected. In contrast, the influence is higher for the deeper and stronger events, such as the first strong earthquake on 26 January 2014. For this strong earthquake three different epicenters were calculated with the use of the 1-D (with the inclusion or the exclusion of distant phases) and 2-D (with all phases) models (Fig. 6). It can be seen how the simplified 1-D velocity model affects the epicenter location when distant phases are taken into account. The error decreases when distant phases are omitted.

We concluded that, for lack of reliable knowledge regarding the structure and velocity of the Moho boundary and in the presence of poor azimuthal seismographic coverage, it is preferable to limit the range of the epicentral distances of stations used and to base the location mostly on the Pg phases.

The data processing has been performed by the NonLinLoc algorithm (Lomax et al., 2000) that follows a non-linear earthquake location method, giving a complete probabilistic solution expressed in terms of a posterior density function (PDF) (Tarantola and Valette, 1982). The function is calculated using the equal differential time (EDT) likelihood function and depicted by confidence ellipsoids. Therefore the higher the confidence of the velocity model, the smaller the ellipsoids of the event locations. This probabilistic approach 

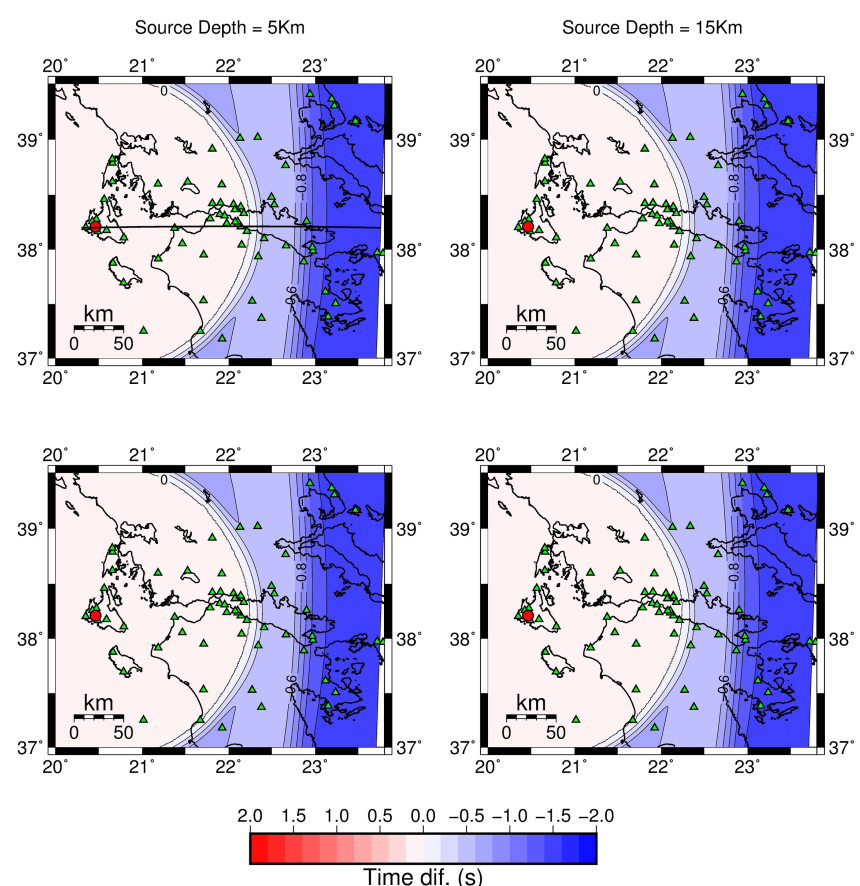

Figure 5. Time differences of $P$-wave (the two panels in the upper row) and $S$-wave (the two panels in the lower panel) arrivals between synthetic data calculated on the basis of the 1-D model and data collected using the 2-D model (based on the same 1-D model but with a non-horizontal Moho boundary). Earthquake focal depths of $5 \mathrm{~km}$ (left column) and $15 \mathrm{~km}$ (right column) are represented. The hypothetical epicenter is shown as a red circle. The errors imported in the case which does not take into account the Moho structure can be significant at long distances.

is characterized by strong advantages compared to linearized methods. More precisely, the EDT function provides a more reliable uncertainty estimate, especially in the presence of outliers, than the conventional least-squares L1 and L2 norms for the misfit calculation between the observed and calculated travel times. Another advantage of the method is that it is independent of origin time, so the 4-D problem of hypocenter location reduces to a 3-D search over spatial location of the hypocenter (latitude, longitude, depth). The NonLinLoc algorithm can also use 2-D and 3-D velocity models.

\subsection{Real data}

For the relocation of the Cephalonia 2014 aftershock sequence, we used NOAGI phase data set consisting of more than $44000 P$-wave and $24000 S$-wave arrivals for the time interval from 26 January to 15 May 2014, corresponding to more than 3300 events. Phase data from distant stations $(\Delta>120 \mathrm{~km})$ were excluded. It should be noted, however, that small magnitude events remained unaffected since they could hardly be identified at greater epicentral distances anyway.

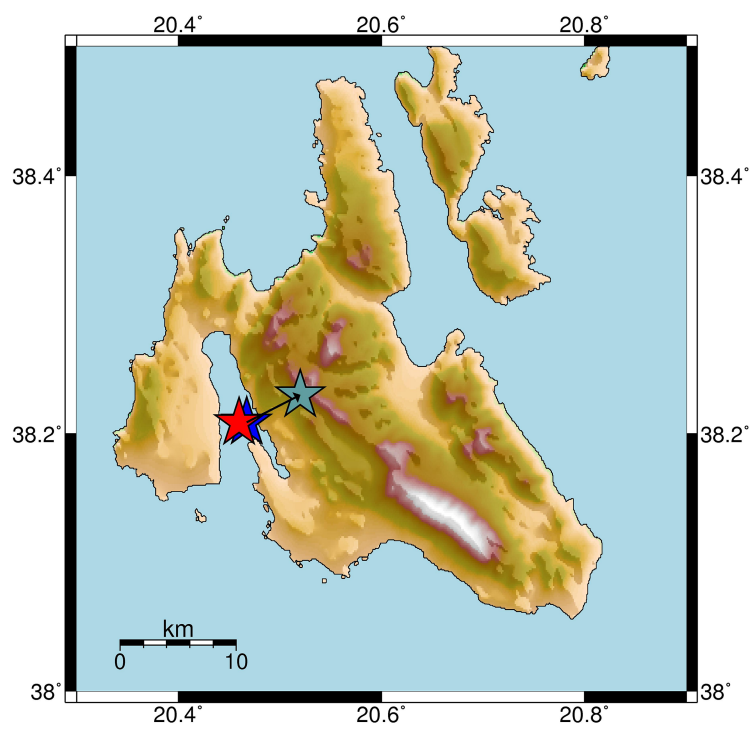

Figure 6. The epicenter of the strong earthquake $\left(M_{\mathrm{W}}=6.0\right)$ on 26 January 2014 calculated with the 1-D model of Haslinger et al. (1999) (see Fig. 3) including distant phases (light blue star at the east), the same 1-D model excluding distant phases (blue star at the west), and the 2-D model (see Fig. 4) including distant phases (red star).

We compared both the 2-D and 1-D versions of the adopted model with the three models proposed by previous authors (Fig. 3). For the comparison we selected events with at least six $P$ - and one $S$-wave arrivals and an azimuthal gap lower than $180^{\circ}$. The station delays were calculated as an average value of observed travel-time residual of the welllocated events (GAP $<180^{\circ}$, RMS $<1 \mathrm{~s}$, horizontal uncertainty ERH and vertical uncertainty ERZ $<1 \mathrm{~km}$ ) and applied to the location procedure. Station corrections compensate for the effect of the station's local geology, which could not be taken into account by the use of a 1-D velocity model. The adopted model succeeds in producing a more compact horizontal projection (Fig. 7) and verifies that the aftershock sequence, trending NNE-SSW, covers only the western part of Cephalonia at a length of about $35 \mathrm{~km}$ and maximum lateral width of about $10 \mathrm{~km}$ (see also Table 1 for the relocated hypocenters of the three major events). It is noteworthy that the relocated aftershock area nearly coincides with the main part of the macroseismic field that is covered by the isoseismal of level V, which is also the area of ground failures produced by the strong earthquakes on 26 January and 3 February 2014 (Papadopoulos et al., 2014).

The model of Haslinger et al. (1999) performs significantly better than those of Hirn et al. (1996), Sachpazi et al. (2000), and that of NOAGI because it is derived from histograms of horizontal and vertical location uncertainties (Table 2). The vast majority (about $80 \%$ ) of the events relocated with the adopted model have a horizontal uncertainty less than $900 \mathrm{~m}$. Moreover, the $52 \%$ of the relocated events 

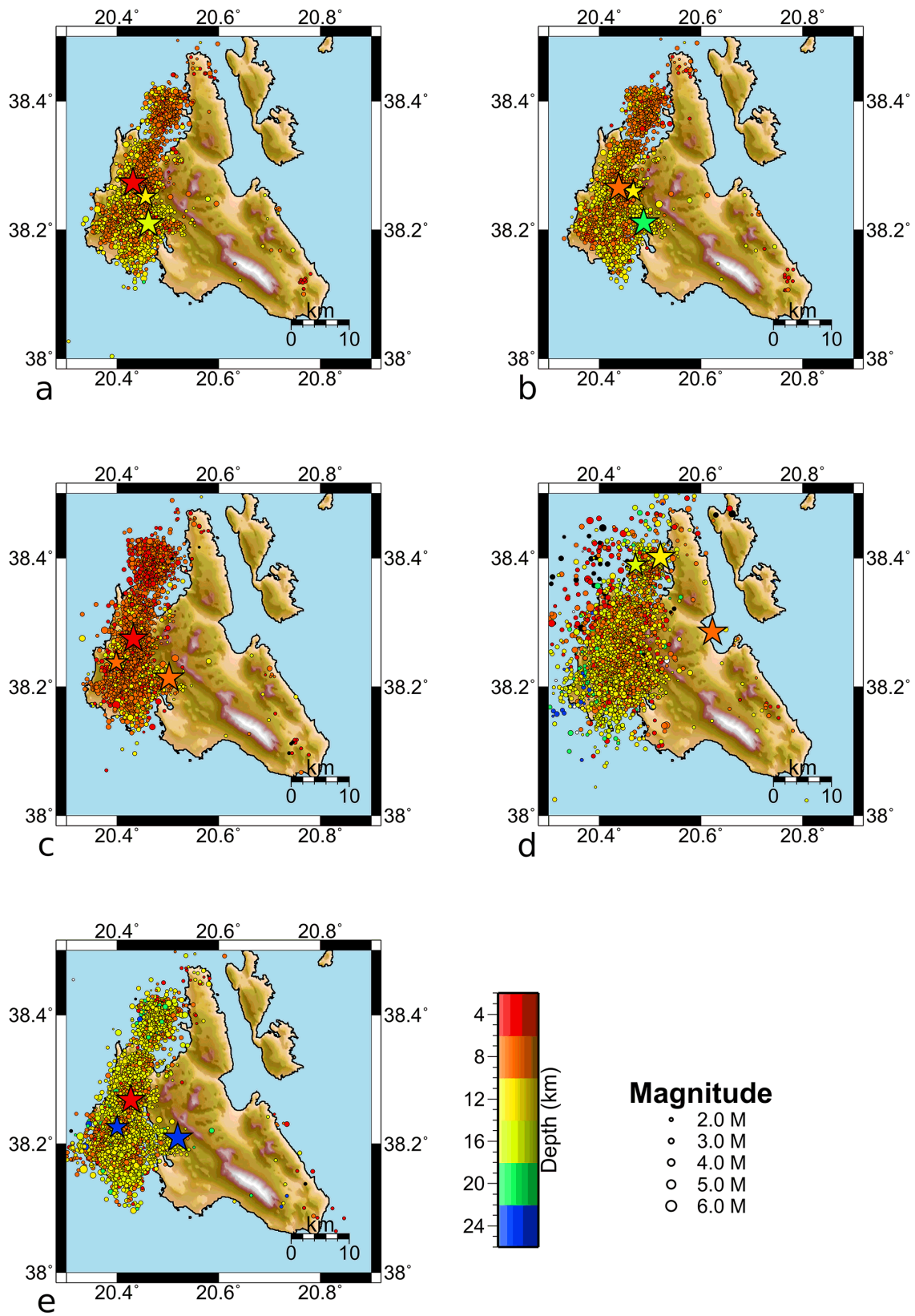

Figure 7. Relocation results by using the velocity models of (a) the 2-D velocity model that resembles the Moho structure, (b) the 1-D velocity model proposed by Haslinger et al. (1999), (c) the 1-D velocity model proposed by Sachpazi et al. (2000), (d) the 1-D velocity model proposed by Hirn et al. (1996), and (e) the 1-D velocity model used by NOAGI for the daily seismic monitoring.

have a horizontal uncertainty less than $600 \mathrm{~m}$ (Table 2). As we can also see in the same table, the original 1-D model of Haslinger et al. (1999) is not notably inferior to the other three models, which produced significantly larger uncertainties. Similar results can be seen also in Fig. 9, depicting the vertical uncertainty distribution (see also Table 2).

For the first $15 \mathrm{~km}$ of depth, the model of Haslinger et al. (1999) has similar velocity values with the model proposed by Hirn et al. (1996), which was produced from re- liable data of seismic reflection profiles. However, there is an obvious discrepancy at depths greater than $15 \mathrm{~km}$. This might be explained by the fact that for these depths, Hirn et al. (1996) used results only from ray-tracing modeling based on common receiver data only from one side (eastern part) of the seismic traverse. In contrast, Haslinger et al. (1999) did not consider an abrupt increase in the velocity structure at $15 \mathrm{~km}$ depth and proposed a Moho boundary at $40 \mathrm{~km}$, whereas Hirn et al. (1996) used a Moho depth at $25 \mathrm{~km}$. The 
Table 2. Distribution of horizontal (ERH) and vertical (ERZ) uncertainties for the events relocated with several seismic velocity models.

\begin{tabular}{lccccc}
\hline Performance & Adopted model & Haslinger et al. (1999) & Sachpazi et al. (2000) & Hirn et al. (1996) & NOAGI \\
\hline ERH $<900 \mathrm{~m}$ & $86 \%$ & $83 \%$ & $71 \%$ & $39 \%$ & $76 \%$ \\
$\mathrm{ERH}<600 \mathrm{~m}$ & $57 \%$ & $57 \%$ & $43 \%$ & $21 \%$ & $46 \%$ \\
$\mathrm{ERZ}<900 \mathrm{~m}$ & $89 \%$ & $87 \%$ & $81 \%$ & $64 \%$ & $68 \%$ \\
$\mathrm{ERZ}<600 \mathrm{~m}$ & $69 \%$ & $67 \%$ & $59 \%$ & $44 \%$ & $43 \%$ \\
RMS SD & 0.063 & 0.065 & 0.119 & 0.488 & 0.086 \\
\hline
\end{tabular}

shallow Moho boundary is likely the main reason for the poor relocation results we obtained from the model of Hirn et al. (1996).

The aftershock focal depths calculated by various models also show significant variations (Fig. 8). The adopted model, as well as that of Haslinger et al. (1999), has the vast majority of focal depths between 6 and $14 \mathrm{~km}$. The model of Sachpazi et al. (2000) calculated a significant percentage of the hypocenters at depths between 4 and $6 \mathrm{~km}$ and a very low percentage with depths greater than $12 \mathrm{~km}$. No hypocenters with unrealistic depth values $(<4)$ were calculated by the models based on Haslinger et al. (1999).

\section{Seismotectonic implications and discussion}

The spatial distribution of the relocated earthquake sequence (Fig. 7a) confirms that the 2014 earthquake activity covers only the western part of Cephalonia Island trending from NNE to SSW at a length of about $35 \mathrm{~km}$ and maximum lateral width of ca. $10 \mathrm{~km}$. No earthquake activity developed off the coast of western Cephalonia. As a consequence, the JanuaryFebruary 2014 earthquake sequence can hardly be seismotectonically associated with the Cephalonia segment of the major right-lateral strike-slip structure of the CTFZ, as the latter was proposed by Louvari et al. (1999). On the contrary, the aftershock pattern implies that the 2014 activity ruptured western Cephalonia due to onshore strike-slip faulting. One possible scenario is that the activated strike-slip faults comprise the southern prolongation of the NNE-SSW trending Lefkada segment of the CTFZ. Papadopoulos et al. (2014) suggested that the Lefkada CTFZ segment does not terminate off the coast of NW Cephalonia, as proposed by previous authors (Louvari et al., 1999), but extends further into western Cephalonia. Another scenario is that the activated strike-slip faults comprise segments of a $30 \mathrm{~km}$, nearly $\mathrm{N}-\mathrm{S}$ trending fault zone that splits the island into a western and an eastern part. The consequence is that western Cephalonia appears as a seismotectonic block independent of eastern Cephalonia, which hosted the sources of the large 1953 earthquakes.

The space-time evolution of the 2014 sequence (Fig. 9), based on the high-precision relocated earthquake catalogue that we produced, indicates that soon after the occurrence of the first strong earthquake on 26 January 2014, the aftershock area was already well shaped. No further expansion of the af-
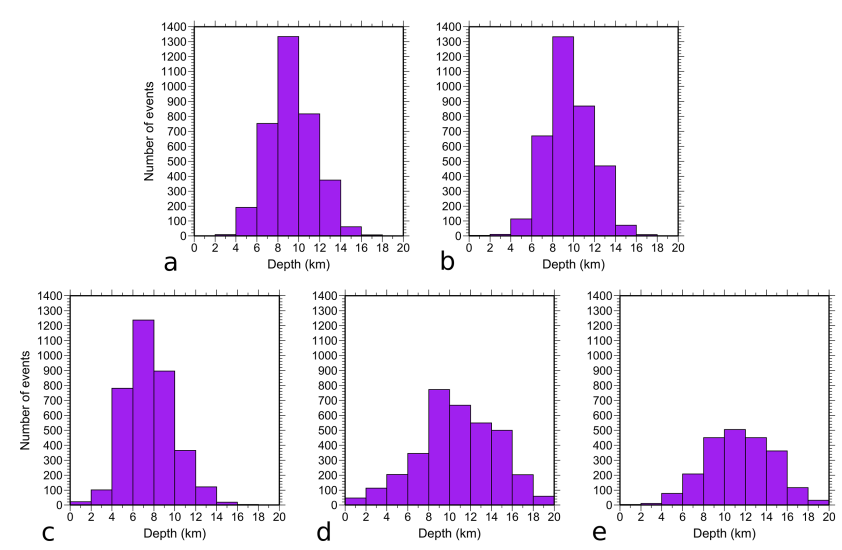

Figure 8. Distribution of hypocentral depth of the relocated Cephalonia 2014 earthquake sequence up to 15 May 2014 for different seismic velocity models: (a) the adopted 2-D model, which is a modification of the Haslinger et al. (1999) model; (b) Haslinger et al. (1999); (c) Sachpazi et al. (2000); (d) Hirn et al. (1996); and (e) the model routinely used in the daily seismic monitoring by NOAGI.

tershock area was observed either after 29 January, when the portable network was installed, or after the strong earthquake on 3 February 2014.

The Cephalonia 2014 sequence is geographically distributed into two clusters (Figs. 7a and 10). The first is small, with a length on the order of $10 \mathrm{~km}$ and occupying the north side of the aftershock cloud. The other extends in the central and south sides, thus leaving an apparent spatial gap between the two clusters. Papadopoulos et al. (2014) suggested that the area of the 2014 gap had already ruptured from the strong $\left(M_{\mathrm{w}}=5.5\right)$ strike-slip earthquake on 25 March 2007. However, no temporal relation was found between these two clusters and the occurrence of the strong events on $26 \mathrm{Ja}-$ nuary and 3 February 2014. The north cluster abuts but does not overlap the southern side of the aftershock area of the strong 2003 Lefkada $\left(M_{\mathrm{w}}=6.2\right)$ main shock (Papadopoulos et al., 2003). Besides, the foreshock activity that preceded the first strong earthquake on 26 January 2014 by about 4 days was recorded exactly in the area of the north (small) aftershock cluster (Papadopoulos et al., 2014). This may indicate that the 2014 activity was initiated at the northern part of the aftershock area where the 2003 Lefkada activity diminished. Therefore, we observe that a shallow tectonic structure exists 

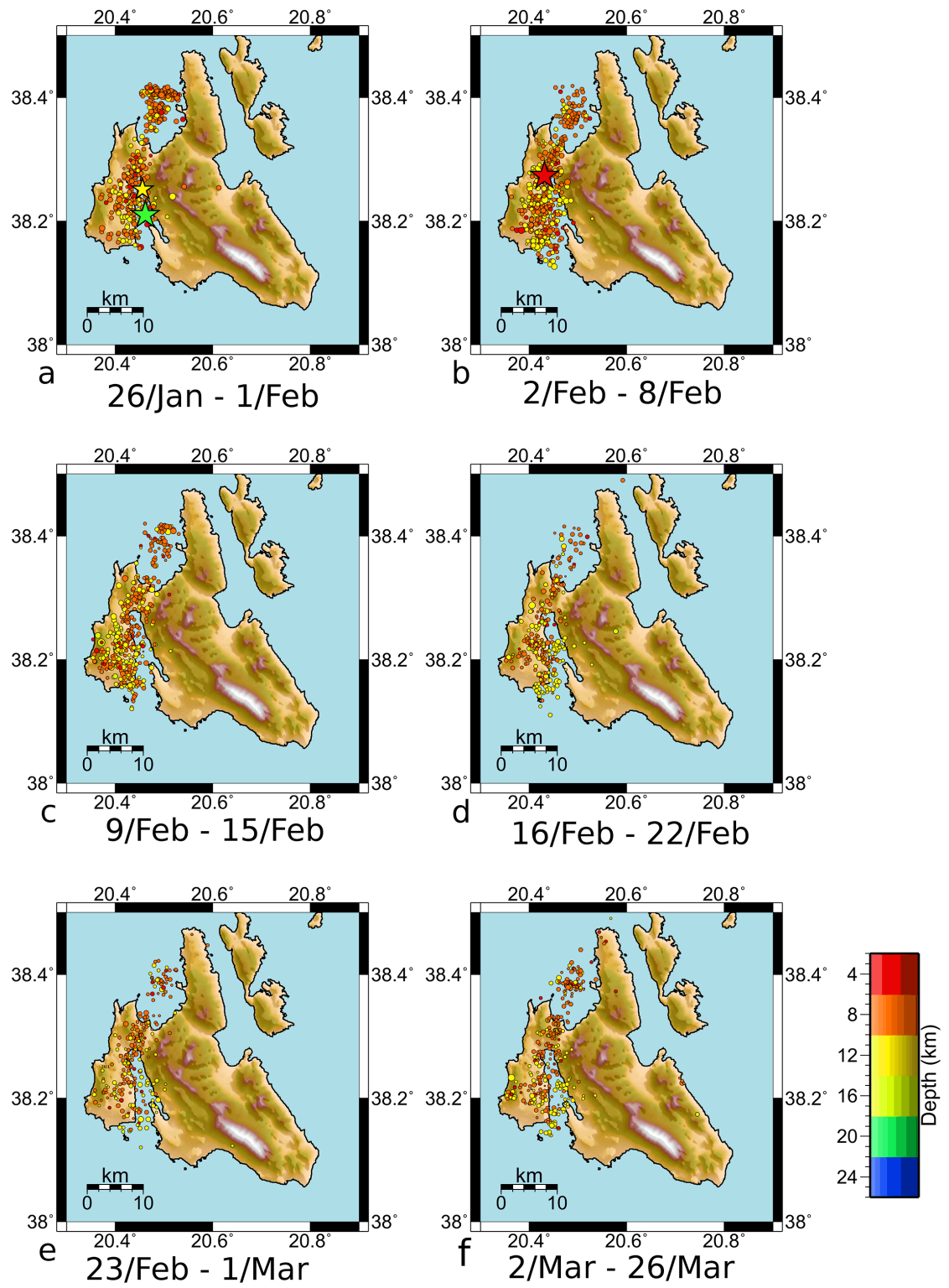

Figure 9. Space-time evolution of the Cephalonia 2014 sequence. The maps show the aftershocks with 1-week time interval (a-f) between 26 January 2014 and 26 March 2014.

in the area of the Myrtos Gulf, possibly a near-vertical fault striking WNW-ESE that is perpendicular to the NNE-SSW strike of the Lefkada 2003 and the Cephalonia 2014 aftershock areas. This fault, which probably controlled the initiation of the 2014 sequence, can be seen in the NNE-SSW cross section in Fig. 10c that depicts clearly the vertical geometry of the EW cross fault at Myrtos Gulf at depths of 5$12 \mathrm{~km}$. Evidence also comes from the space-time evolution of the relocated 2014 sequence (Fig. 9), but further examination is needed.

With the relocation applied, the foci of the three strongest earthquakes of the sequence shifted at shallower depths, while the first strong earthquake on 26 January 2014 also shifted towards WNW with respect to the preliminary deter- minations (Table 1). The thickness of the seismogenic layer does not exceed $16 \mathrm{~km}$. That the 2014 aftershock area was well formed from the very beginning without spatial expansion after the strong earthquake on 3 February 2014 provides evidence that this earthquake ruptured within the aftershock volume of the 26 January 2014 earthquake, the largest event of the sequence. From this point of view we may consider that the 3 February event was the strongest aftershock of the sequence that ruptured at a shallower depth and at a different fault from that of the main shock on 26 January 2014.

To further control the fault patterns associated with the 26 January and 3 February earthquakes, we constructed two respective vertical cross sections as shown in Fig. 10. One may observe that in the section corresponding to the main 
Table 3. Mean horizontal and absolute source location distances between the adopted model and the other seismic velocity models.

\begin{tabular}{lcccc}
\hline & Haslinger et al. (1999) & Sachpazi et al. (2000) & Hirn et al. (1996) & NOAGI \\
\hline Mean horizontal distance $(\mathrm{km})$ & 0.7 & 1.8 & 5.3 & 2.4 \\
Mean absolute distance $(\mathrm{km})$ & 2.5 & 3.1 & 7.1 & 3.7 \\
\hline
\end{tabular}
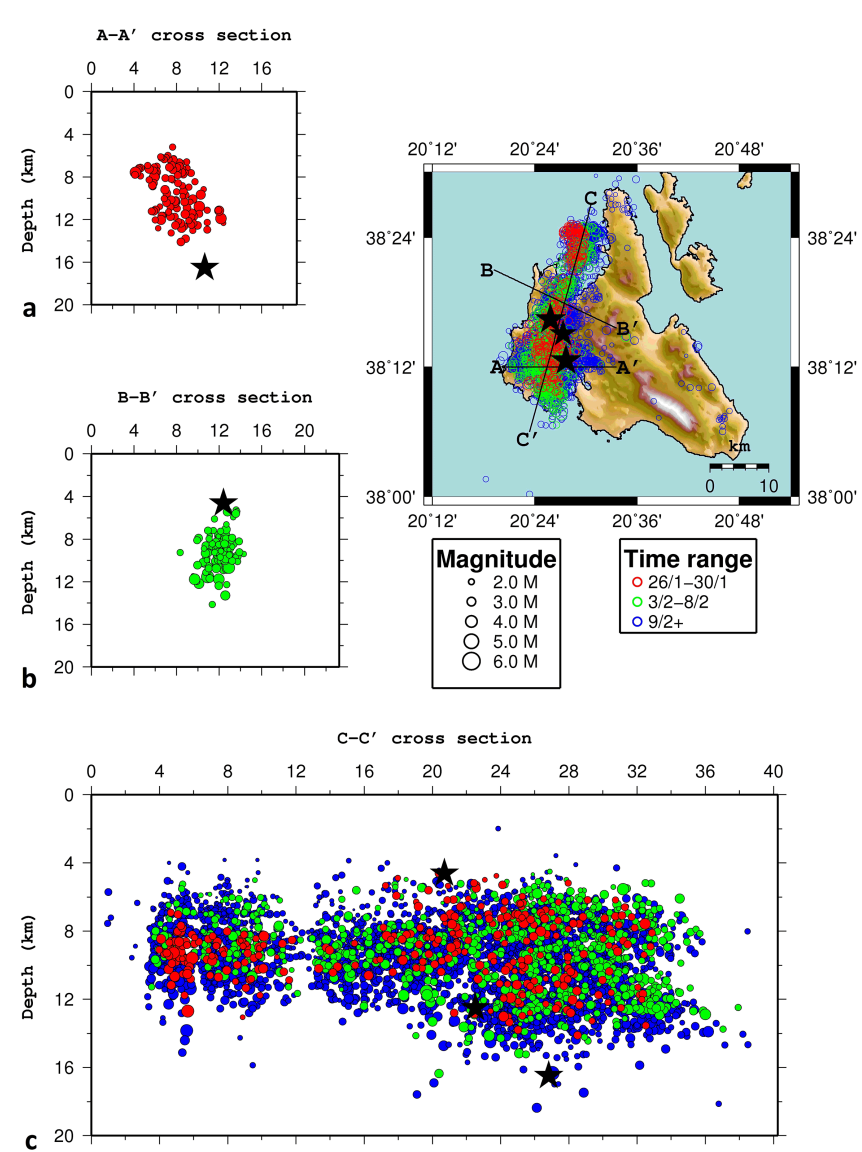

Figure 10. Vertical sections of the aftershock sequence and their location on the map: (a) the hypocenters (with GAP $<180^{\circ}$ ) between 26 and 30 January 2014; (b) the hypocenters (with GAP $<180^{\circ}$ ) between 3 and 8 February 2014; and (c) the hypocenters (with GAP $<180^{\circ}$ ) for the whole sequence (26 January-15 May 2014).

shock on 26 January, the aftershocks until 30 January included in a $\pm 4 \mathrm{~km}$ wide zone seem arranged in a plane of nearly $\left(+/-10^{\circ}\right) \mathrm{N}-\mathrm{S}$ and dip of about $65^{\circ}$ to the east (Fig. 10a). The preferred fault-plane adopted by Papadopoulos et al. (2014) and Valkaniotis et al. (2014) is of strike $23^{\circ}$ and $\operatorname{dip} 68^{\circ}$ to the east, which is consistent with the geometry represented by the vertical section. However, the vertical section through the hypocenter of the 3 February 2014 event (Fig. 10b) shows that the fault plane strikes nearly $\left(+/-10^{\circ}\right) \mathrm{N}-\mathrm{S}$ but its dip is about $65^{\circ}$ to the west. The geometry of this fault plane is compatible with the fault plane that dips $56^{\circ}$ to the west according to the focal mechanism computed by the GFZ $\left(183^{\circ} / 56^{\circ} / 138^{\circ}\right.$; reported on the European-Mediterranean Seismological Centre website (2015). The western dip in combination with the oblique-slip rake may result in uplift of the hanging wall (western) of the $\mathrm{N}-\mathrm{S}$ fault during co-seismic motion.

Our relocation procedure suggests a different fault model than that of Karakostas et al. (2014; their Fig. 8), who suggested a right step of CTFZ, on the Paliki peninsula. Contrarily, we detected the activation of two blind strike-slip faults along the $\mathrm{N}-\mathrm{S}$ axis at the Myrtos Gulf-Lixouri line, possibly overlapping with a left step. The 26 January 2014 activated fault (Fig. 10a) is in agreement with the blind fault model of Valkaniotis et al. (2014). Such a fault configuration may explain the co-seismic uplift seen on the Paliki peninsula in InSAR data (Boncori et al., 2015) because our relocation data in the epicentral region of the 3 February 2014 event point to a west-dipping fault (Fig. 10b). If this is the case, then the hanging wall of this fault moved upwards during co-seismic motion; it is known that Cephalonia region is in state of compression with maximum horizontal stress oriented at $\mathrm{N} 78^{\circ} \mathrm{E}$ $\left(+/-9^{\circ}\right.$; Ganas et al., 2013), as determined from GPS data. In addition, Lagios et al. (2012) obtained a N-S discontinuity in their horizontal velocity field (see Fig. $4 \mathrm{c}$ of Lagios et al., 2012) across the Gulf of Argostoli, which may be indicative of a crustal block boundary or a large fault zone beneath the Gulf.

\section{Conclusions}

1. The strong earthquakes on Cephalonia on 26 January and 3 February 2014 clearly show the problem of incorrect hypocentral determination for earthquakes that occur at the borders of the seismograph network of Greece, near the region of convergence of the tectonic plates when an oversimplified 1-D velocity model is used.

2. We propose a 2-D velocity model with a non-horizontal Moho boundary that resembles the crustal thinning of the Hellenic Arc region.

3. We applied a relocation procedure in the 2014 Cephalonia sequence for the time period from 26 January to 15 May 2014 by applying probabilistic non-linear location algorithms. The thickness of the seismogenic layer of the upper (Aegean) plate does not exceed $16 \mathrm{~km}$. 
4. The distribution of the relocated epicenters covers only the western part of Cephalonia, trending NNE-SSW for about $35 \mathrm{~km}$ with a lateral width of ca. $10 \mathrm{~km}$.

5. The 2014 earthquake sequence is associated with dextral, strike-slip faults on the island of Cephalonia. Moreover, a vertical section through the hypocenter of the 3 February 2014 event shows that the fault plane strikes nearly $\mathrm{N}-\mathrm{S}$ but its dip is about $65^{\circ}$ to the west.

6. Our relocated hypocentral distribution delineates a shallow, near-vertical fault existing in the area of Myrtos Gulf, striking WNW-ESE, perpendicular to both the strike of the Lefkada 2003 and the Cephalonia 2014 aftershock areas.

Acknowledgements. Thanks are extended to the acting director and the staff of the Institute of Geodynamics for the daily processing of many seismic phases as well as for the installation of the portable network in Cephalonia. Thanks are also due to the topical editor of the journal, Takaaki Taira, for his suggestions on improving the original manuscript. We would also like thank Ivan Koulakov and the anonymous reviewer for the thorough review of the manuscript and their constructive comments.

Edited by: T. Taira

\section{References}

Ambraseys, N.: Earthquakes in the Mediterranean and Middle East, Cambridge University Press, New York, 8, 4333-4355, 2009.

Bohnhoff, M., Makris, J., Papanikolaou, D., and Stavrakakis, G.: Crustal investigation of the Hellenic subduction zone using wide aperture seismic data, Tectonophysics, 343, 239-262, 2001.

Boncori, J. P. M., Papoutsis, I., Pezzo, G., Tolomei, C., Atzori, S., Ganas, A., Karastathis, V., Salvi, S., Kontoes, C., and Antonioli, A.: The February 2014 Cephalonia Earthquake (Greece): 3D Deformation Field and Source Modeling from Multiple SAR Techniques, Seismol. Res. Lett., in press, 2015.

Eberhart-Phillips, D.: Three-dimensional $\mathrm{P}$ and $\mathrm{S}$ velocity structure in the Coalinga Region, California, J. Geophys. Res., 95, 1534315363, 1990.

Eberhart-Phillips, D.: Local earthquake tomography: earthquake source regions, in: Seismic Tomography: Theory and Practice, edited by: Iyer, H. M. and Hiahara, K., Chapman and Hall, London, 613-643, 1993.

EPPO-ITSAK: The January 26th, 2014 Earthquake in Cephalonia, Preliminary Report, by EPPO-ITSAK, available at: http://www.slideshare.net/itsak-eppo/ 2014-0127-kefaloniaeqpreliminaryreporta, last access: 28 January 2015, 2014a (in Greek).

EPPO-ITSAK: Strong Ground Motion of the February 3, 2014 Cephalonia Earthquake: Effect on Soil and Built Environment in Combination with the January 26, 2014 Event, available at: http://www.slideshare.net/itsak-eppo/ 20140203-kefaloniaeq-report-en, last access: 28 January 2015, 2014b.
European-Mediterranean Seismological Centre website: Full tensors solutions (event 20140203 03:08), http://www.emsc-csem. org/Earthquake/mtfull.php?id=357329, last access: 28 January 2015.

Ganas, A., Marinou, A., Anastasiou, D., Paradissis, D., Papazissi, K., Tzavaras, P., and Drakatos, G.: GPS-derived estimates of crustal deformation in the central and north Ionian Sea, Greece: 3 -yr results from NOANET continuous network data, J. Geodynamics, 67, 62-71, 2013.

Ganas, A., Karastathis, V., Moshou, A., Valkaniotis, S., Mouzakiotis, E., and Papathanassiou, G.: Aftershock properties and seismotectonic setting of the 7 August 2013 moderate earthquake in Kallidromon Mountain, central Greece, Tectonophysics, 617, 101-113, 2014.

Haslinger, F., Kissling, E., Ansorge, J., Hatzfeld, D., Papadimitriou, E., Karakostas, V., Makropoulos, K., Kahle, H. G., and Peter, Y.: 3D crustal structure from local earthquake tomography around the Gulf of Arta (Ionian region, NW Greece), Tectonophysics, 304, 201-218, 1999.

Hatzfeld, D., Kassaras, I., Panagiotopoulos, D., Amorese, D., Makropoulos, K., Karakaisis G., and Coutant, O.: Microseismicity and strain pattern in northwestern Greece, Tectonics, 14, 773785, 1995.

Hellenic Unified Seismological Network: Webpage of Hellenic Unified Seismic Network (H.U.S.N.) hosted in the website of Institute of Geodynamics, of National Observatory of Athens: http: //www.gein.noa.gr/en/networks/husn/, last access: 28 January 2015.

Hirn, A., Sachpazi, M., Siliqi, R., Bride, J. M., Marnelis, F., Cernobori, L., and STREAMERS-PROFILES group: A traverse of the Ionian islands front with coincident normal incidence and wideangle seismics, Tectonophysics, 264, 35-49, 1996.

Karagianni, E. E., Papazachos, C. B., Panagiotopoulos, D. G., Suhadolc, P., Vuan, A., and Panza, G. F.: Shear velocity structure in the Aegean area obtained by inversion of Rayleigh waves, Geophys. J. Int., 160, 127-143, 2005.

Karakostas, V., Papadimitriou, E., Mesimeri, M., Gkarlaouni, C., and Paradisopoulou, P.: The 2014 Kefalonia doublet (Mw 6.1 and Mw 6.0), Central Ionian Islands, Greece: Seismotectonic implications along the Kefalonia transform fault zone, Acta Geophys., 1-16, 2014.

Karastathis, V. K., Papoulia, J., Di Fiore, B., Makris, J., Tsambas, A., Stampolidis, A., and Papadopoulos, G. A.: Deep structure investigations of the geothermal field of the North Euboean Gulf, Greece, using 3-D local earthquake tomography and Curie point depth analysis, J. Volcanol. Geoth. Res., 206, 106-120, 2011.

Kissling, E.: Velest User's Guide, Institute of Geophysics, ETH Zurich, Switzerland, 26 pp., http://www.seg.ethz.ch/software/ velest_guide.pdf, 1995.

Kissling, E., Ellsworth, W. L., Eberhart-Phillips, D., and Kradolfer, U.: Initial reference models in local earthquake tomography, J. Geophys. Res., 99, 19635-19646, 1994.

Kokinou, E., Kamberis, E., Vafidis, A., Monopolis, D., Ananiadis, G., and Zelelidis, A.: Deep seismic reflection data Greece: a new crustal model for the Ionian sea, J. Petrol. Geol., 28, 81-98, 2005.

Koulakov, I.: LOTOS code for local earthquake tomographic inversion: benchmarks for testing tomographic algorithms, B. Seismol. Soc. Am., 99, 194-214, 2009. 
Koulakov, I. and Sobolev, S. V.: Moho depth and three-dimensional $\mathrm{P}$ and $\mathrm{S}$ structure of the crust and uppermost mantle in the Eastern Mediterranean and Middle East derived from tomographic inversion of local ISC data, Geophys. J. Int., 164, 218-235, 2006.

Lagios, E., Papadimitriou, P., Novali, F., Sakkas, V., Fumagalli, A., Vlachou, K., and Del Conte, S.: Combined Seismicity Pattern Analysis, DGPS and PSInSAR studies in the broader area of Cephalonia (Greece), Tectonophysics, 524, 43-58, 2012.

Le Meur, H., Virieux, J., and Podvin, P.: Seismic tomography of the Gulf of Corinth: a comparison of methods, Ann. Geophys.-Italy, 40, 1-24, 1997.

Lippitsch, R., White, R. S., and Soosalu, H.: Precise hypocentre relocation of microearthquakes in a high temperature geothermal field: the Torfajökull central volcano, Iceland. Geophys. J. Int, 160, 371-388, 2005.

Lomax, A., Virieux, J., Volant, P., and Berge-Thierry, C.: Probabilistic earthquake location in 3-D and layered models, in: Advances in Seismic Event Location, edited by: Thurber, C. H. and Rabinowitz, N., Kluwer Academic Publishers, Dordrecht/Boston/London, 101-134, 2000.

Louvari, E., Kiratzi, A. A., and Papazachos, B. C.: The CTF and its extension to western Lefkada Island, Tectonophysics, 308, 223236, 1999.

Makris, J.: Crustal Structure of the Aegean Sea and the Hellenides Obtained from Geophysical Survey, J. Geophys., 41, 441-443, 1975.

Makris, J.: A dynamic model of the Hellenic arc deduced from geophysical data, Tectonophysics, 36, 339-346, 1976.

Makris, J.: Geophysical Investigations of the Hellenides, Hamburger Geophysikalische Einzelschriften, G. M. L. Wittenborn Söhne, Hamburg, Heft 34, 124 pp., 1977.

Makris, J.: The crust and upper mantle of the Aegean region from deep seismic soundings, Tectonophysics, 46, 269-284, 1978.

Makris, J., Papoulia, J., and Yegorova, T.: A 3-D density model of Greece constrained by gravity and seismic data, Geophys. J. Int., 194, 1-17, 2013.

NOA web report, internal report, available at: http://www.gein.noa. gr/Documents/pdf/Cefalonia_20140126_preliminary_web.pdf (last access: 4 June 2014), 2014a.

NOA web report, internal report, available at: http://www.gein.noa. gr/Documents/pdf/Cefalonia_20140203_preliminary_web.pdf (last access: 4 June 2014), 2014b.

Papadopoulos, G. A., Karastathis, V. K., Ganas, A., Pavlides, S., Fokaefs, A., and Orfanogiannaki, K.: The Lefkada, Ionian Sea (Greece), shock (Mw 6.2) of 14 August 2003: Evidence for the characteristic earthquake from seismicity and ground failures, Earth Planet. Space, 55, 713-718, 2003.

Papadopoulos, G. A., Karastathis, V. K., Koukouvelas, I., Sachpazi, M., Baskoutas, I., Chouliaras, G., Agalos, A., Daskalaki, E., Minadakis, G., Moschou, A., Mouzakiotis, E., Orfanogiannaki, A., Papageorgiou, A., Spanos D., and Triantafyllou, I.: The Cephalonia, Ionian Sea (Greece), sequence of strong earthquakes of January-February 2014: a first report, Res. Geophys., 4, 1930, 2014.

Papazachos, B. C. and Papazachou C. B.: The Earthquakes of Greece, Ziti Editions, Thessaloniki, 2003 (in Greek).
Papazachos, B. C., Comninakis, P. E., Scordilis, E. M., Karakaisis, G. F., and Papazachos C. B.: A catalogue of earthquakes in the Mediterranean and surrounding area for the period 1901-2010, Publ. Geophys. Laboratory, University of Thessaloniki, Greece, 2010.

Papazachos, C. B. and Nolet, G.: P and S deep velocity structure of the Hellenic area obtained by robust nonlinear inversion of travel times, J. Geophys. Res., 102, 8349-8367, 1997.

Pearce, F. D., Rondenay, S., Sachpazi, M., Charalampakis, M., and Royden, L. H.: Seismic investigation of the transition from continental to oceanic subduction along the western Hellenic Subduction Zone, J. Geophys. Res., 117, 1978-2012, 2012.

Podvin, P. and Lecomte, I.: Finite difference computation of traveltimes in very contrasted velocity models: a massively parallel approach and its associated tools, Geophys. J. Int., 105, 271-284, 1991.

Sachpazi, M., Hirn, A., Clement, C., Laigle, M., Haslinger, F., Kissling, E., Charvis, P., Hello, Y., Lepine, J., Sapine, M., and Ansorge, J.: Western Hellenic subduction and Cephalonia transform: local earthquakes and plate transport and strain, Tectonophysics, 319, 301-319, 2000.

Scordilis, E. M., Karakaisis, G. F., Karakostas, B. G., Panagiotopoulos, D. G., Comninakis, P. E., and Papazachos, B. C.: Evidence for Transform Faulting in the Ionian Sea: the Cephalonia Island Earthquake Sequence of 1983, Pure Appl. Geophys., 123, 388397, 1985.

Sodoudi, F., Kind, R., Hatzfeld, D., Priestley, K., Hanka, W., Wylegalla, K., Stavrakakis, G., Vafidis, A., Harjes H.-P., and Bohnhoff, M.: Lithospheric structure of the Aegean obtained from $\mathrm{P}$ and S receiver functions, J. Geophys. Res., 111, B12307, doi:10.1029/2005JB003932, 2006.

Tarantola, A. and Valette, B.: Inverse problems = quest for information, J. Geophys., 50, 159-170, 1982.

Thurber, C. H.: Local earthquake tomography: velocities and $V_{\mathrm{p}}=$ $V_{\mathrm{S}}$ - theory, in: Seismic Tomography: Theory and Practice, edited by: Iyer, H. M. and Hiahara, K., Chapman and Hall, London, 563-583, 1993.

Tiberi, C., Diament, M., Lyon-Caen, H., and King, T.: Moho topography beneath the Corinth Rift area (Greece) from inversion of gravity data, Geophys. J. Int., 145, 797-808, 2001.

Tirel, C., Gueydan, F., Tiberi, C., and Brun, J. P.:. Aegean crustal thickness inferred from gravity inversion. Geodynamical implications, Earth Planet. Sc. Lett., 228, 267-280, 2004.

Tsokas, G. N. and Hansen, R. O.: Study of the crustal thickness and the subducting lithosphere in Greece from gravity data, J. Geophys. Res., 102, 20585-20597, 1997.

Underhill, J. R.: Late Cenozoic deformation of the Hellenide foreland, western Greece, Geol. Soc. Am. Bull., 101, 613-634, 1989.

Valkaniotis, S., Ganas, A., Papathanassiou, G., and Papanikolaou, M.: Field observations of geological effects triggered by the January-February 2014 Cephalonia (Ionian Sea, Greece) earthquakes, Tectonophysics, 630, 150-157, doi:10.1016/j.tecto.2014.05.012, 2014.

Yem, L. M., Camera, L., Mascle, J., and Ribodetti, A.: Seismic stratigraphy and deformational styles of the offshore Cyrenaica (Libya) and bordering Mediterranean Ridge, Geophys. J. Int., 185, 65-77, 2011. 